\title{
Mobile based library services
}

\author{
Hansaben Shashikantbhai Bhoj
}

Librarian, Dept. of Central Library, College of Dental Science and Hospital, Madhya Pradesh, India

\author{
*Corresponding Author: Hansaben Shashikantbhai Bhoj
}

Email: hansa1414@gmail.com

\begin{abstract}
The application of mobile phone technology in all aspects of our everyday life cannot be ignored in institutions and establishments including libraries. Therefore libraries in developed economies have embraced the mobile phone revolution and are utilizing them for effective and efficient services. In contrast, however, mobile - based services are not pervasive among academic libraries in India. They are yet to be embraced by academic and research libraries. This paper reports findings of a survey on mobile - based library services in various libraries of India. The aim of the study was to seek the views of users regarding the use of mobile phones in library services. It sought to find whether they would be interested in using such service.
\end{abstract}

Keywords: Mobile phones, Technology, Academic libraries, Library services, University.

\section{Introduction}

The wireless technology and mobile phones are becoming an integral part of everyday life. Mobile phones have wide variety of applications. Mobile technology has made communication and information access very convenient and timely to users from the comfort of their own homes and offices. Already mobile devices have made significant impact on banking, tourism and health services. As today's cellular phones have more features and capabilities than ever before.

People use a mobile phone as their primary interface for surfing the Web, listening to music, watching television, reading books, and interacting with friends. So the mobile phone has become one of the major interfaces people use to access and share information.

Libraries are social institutions, connecting people with people and people with information. It is a time for libraries to take advantage of mobile technology. Mobile Technology will help both beginner and experienced librarians to stay relevant in the mobile society. They need to be aware of technological changes for the future of library mobile interaction. Librarians must be proportionate with this trend and integrate themselves into the mobile realm if they wish to deliver enhanced user services. Mobile devices and services offer wonderful flexibility for those who want to take advantage of library services. With a simple $3 \mathrm{G} / 4 \mathrm{G}$ connection, a user can access e-books and multimedia content from a local library. When one thinks of mobile technologies, the first device that comes to mind has to be the cell phone or the Smartphone. Beginners to the Smartphone in the library may want to consider a mobile based website, a strippeddown design that reads well on small screens. These sites do not require too much web design knowledge (remember that well-designed mobile sites do not have complicated code or scripting languages) and can be designed in-house (Kate Kosturski \& Frank Skornia, 2011) Library policies and services should be flexible and open so that new information needs of users in pursuit of organizational needs are met with new technologies. The task of libraries is to exploit new technology in a more effective way to promote and integrate them into the design of future library services in a cost efficient manner (S Malathy \& P Kantha, 2013). Indian libraries need to be indispensable to their users, and to this end they have to include mobile devices as part of their strategic thinking. Mobile libraries have to grow, and this requires greater collaboration between academic, industry, corporations and government. In the current scenario, mobile libraries have the potential to proliferate and we will witness a situation in which the mobile will definitely be used as a tool to spread learning across the country (Mohan Lal Vishwakarma, Shyam Lal Maurya \& Shivani Govil, 2013).

Mobile devices today can run increasingly complex software, interact with cloud services, play rich multimedia content, and allow for advanced user interactivity. New hardware and technologies such as Bluetooth, accelerometers, and multi touch screens, as well as text messaging, smart phone software applications, mobile websites, global positioning systems (GPS), Wi-Fi, and media creation and capture tools, are all part of the mobile environment. Many of today's mobile devices are increasingly "always on", that is, by default meant to be connected to a wireless network (Srinivasa Rao Nalluri \& Brahmaiah Gaddam, 2016).

\section{Library services through mobile technology}

Library services that can be provided via mobile technology are as follows.

1. SMS notification services- Libraries may provide the alerts on latest news, events and notices via SMS and MMS to users wherever they might be go. The users can get notified instantly with notice alerts such as- alerts on bringing new books to the notice of users for suggestion, intimation of arrival of indented documents by users, informing availability of reserved documents for collection, appraising about overdue books, outstanding fines, reminders to return library items, renew books, library circulars, ejournals subscribed, change in timings, information about important events, loan request etc. Such alert notifications can be generated automatically using integrated library management system/software. SMS messages can be sent to group of 
users simultaneously through many free applications and intermediary websites/clients.

2. Formal Education, Distance Learning and Elearning- Students are very versatile in using their mobile phones and various mobile applications. Academic libraries can harness the advantage to lead implementation of library services through mobile devices to support distance learning, formal education, and research activities in e-learning environment by making the information resources ubiquitous. Library services should also blend with teaching and research practice of colleges/universities, scientific community or other patrons whom they serve.

3. Database Browsing- Libraries provide access to a variety of its resources and databases. The users can just enter search terms and see results that are designed specifically for mobile viewing. This service includes OPAC (online public access catalogue), integrated search, and original document search. OCLC ${ }^{\mathrm{ee}} \mathrm{S}$ WorldCat Mobile application allows users to search for and find books and other materials available in their local libraries through a web application they can access from a PDA or a smart phone.

4. My library- My library is a personal library space where users can find information and resources of their choosing. Users can read alerts, check records, renew resources, request items, track interlibrary loans and document delivery requests, set up email notices of new books and journal articles, set up preferences for catalogue searching, etc.

5. E-resources with Mobile Interfaces- Some publishers are already delivering e-books (both text and audio) that are accessible via mobile phones. It offers access to a variety of databases and digital resources such as eBooks, e-Journals, Web databases, dissertations, audio books, streaming music, films, images and article databases which can be used on mobile. These collections can either be downloaded from the library websites on users own mobile devices or libraries lend mobile devices with the collections already on them. A large collection of audio books both free-and subscription based services are available for download and also transferable to mobile devices. Libraries can make use of multimedia messaging service (MMS) on mobile devices to share photos, videos, and audio. Most of the e-book publishers provide $24 \times 7$ accesses to the library subscriptions from any internet terminal within the campus, as well on mobile devices, such as iPads, Android devices, and Kindle.

6. Library guide- Libraries can give users the best of library guide information such as library use guide, question answering service, and library statistics delivering rich content in a way that works best for users. If users have questions and want to contact the librarian for help, they can get a fast response from the library via the mobile device and find the appropriate information needed.
7. Mobile document supply- The mobile environment and technology present new opportunities for sending document requests and scanned images and monitoring the use of collections as well as the automation of administrative operations. It can support electronic funds transfer, supply chain management, e-marketing, online marketing, online transaction processing, electronic data interchange, and automated inventory management systems.

8. Text reference service- If the library receives a high volume of enquiries that require brief responses, such as dictionary definitions, facts or service information then Librarians can provide instant answers, and links to articles/references in real time.

9. Library Virtual/ Audio Tours- Library Virtual/ Audio tours, instruction/induction/orientation programs have been quite significant in bringing the nonusers to libraries and also help the remotely located or users located in different geographical locations. Library users, who don't have time or inclination to attend an onsite workshop, can get access to library tours on their mobile devices. Audio/ virtual library tours spent helping new users to orient themselves in the library and explaining the facilities available. It can easily be provided both as downloads from the library website and on mobile devices.

10. QR Codes on Mobiles- QR code stands for "quick response", and basically two-dimensional bar codes that can contain any alphanumeric text and often used to store URL's, text, etc., known as “mobile tagging". Data can be translated into a QR code by any QR generator, many of which are available as free download. Users simply enter the data to be translated, and the generator produces the code, which can then be displayed electronically or in printed format. Decoding the information can be done with any mobile camera phone that has a $\mathrm{QR}$ reader, which is freely available online for most devices.

\section{Mobile technology implementation advantages in libraries}

Advantages of implementation of mobile technology in libraries are as follows.

1. User-friendly- Familiarity with their own devices and technology helps the users in accessing information quickly and does not require orientation and training. Mobile users are using the facilities on mobile phones like SMS, instant messaging, web browsing, e-mail effortlessly to communicate. Most of these features are pre-installed on mobile devices or option for data plan packages.

2. Personalized Service- Personalized service helps users to interact with library staff to seek specific information or reference away from library.

3. Ability to Access Information- Information access from anywhere at any time will be of great help for users who cannot visit library in person and provides a constant link to required information resources. 
4. Time Saving- Users need not record information about resources while browsing and searching library resources or wait at library transaction counter to renew/reserve books and hence the time of the user is saved.

5. User Participation- Libraries can enrich OPAC by allowing users to incorporate user created content like notes or images uploaded by users.

6. Location Awareness- Mobile communication enables libraries to offer location-based services/content through global positioning system (GPS) capabilities. Libraries can guide the users to the location of specific document or service through maps and navigational tools.

7. Limitless Access- All online resources accessible on their desktop also become accessible through mobiles.

8. Access to Print-disabled- Users Mobiles communications help providing services orally to visiondisabled and physically challenged users.

\section{Applications, Mobile websites \& OPACs}

There are Mobile websites, OPACs and applications for library use. The following are the list of Mobile websites, OPACs and applications.

1. Android Developers: It provides Resources for creating Android applications. Includes developer's guide, tutorials, and videos.

2. AirPac (Innovative Interfaces): It offers a mobile version of the Innovative Interfaces (III) library catalogue. Includes features such as cover images, integrated library locations with Google Maps software, request and renew items, and more. Contact Innovative Interfaces for pricing.

3. Boopsie: It is specializing in public and academic libraries and universities, Boopsie can deliver mobile applications that are compatible with all Web-enabled phones. Contact the site for a price quote.

4. JQTouch: Freelance Web Designer and Developer Matthew Leak outlines one way to create an iphonefriendly version of a Web site.

5. Library Anywhere: Library anywhere is a mobile catalogue for any library. It includes mobile Web and apps for iphone, Blackberry, and Android.

6. MobileTuts+: It provides tutorials for all mobile developers, regardless of platform. Topics include techniques for building mobile apps and mobile Web sites.

7. MobiSiteGalore: It helps to build a mobile Web site in less than 60 minutes. No technical or programming knowledge required.

8. MoFuse: It helps to build a mobile version of an existing Web site or blog with the MoFuse (short for Mobile Fusion) content management platform.

9. Mobile Web Best Practices 1.0: It is created by the World Wide Web Consortium (W3C); this document specifies guidelines for developing Web-based content for mobile devices.

10. W3C MobileOK Checker: It helps to validate mobileoptimized Web sites for compatibility with current Web standards. Results include severity, category, and description of the error along with best practices for fixing issues.

11. V. Benefits of the mobile web: The mobile web is internet for the small screen, and thus provides many of the same benefits as its desktop counterpart, such as:

- Constant connectivity: Web enabled mobile devices provide owners with around the clock access to the internet, regardless of location.

- Location awareness: Many of today's smart phones and pocket PCs have global positioning systems (GPS) capabilities which make them aware of where they are at all times.

- Limitless access: The mobile web encompasses not only those sites that have been specially designed for mobile browsing, but also the World Wide Web.

- Interactive capabilities: The mobile web offers users the participatory experience of the read/write web in the palm of their hand. Users can create content, share and rate media, make comments, write blog posts, tag resources, and form connections on social networks.

\section{Conclusion}

The active nature of technology has significant impact on every aspect of modern life. Particularly information and communication technologies (ICT) have provided faster access to information and it is also demanding the libraries to rethink and modernize their services adopting the technological changes. In the present world, libraries are not solo information providers. Internet facilities provide broad range of information; the content may not always be free or with value addition. To target its place as an information provider, libraries must not hesitate to adopt all possible new technologies like ICT, Wi-Fi, mobile communications, etc,. There is a greater influence of mobile technology on Libraries, particularly as network access becomes more affordable and reliable, the libraries can adapt to this emerging trend to make the libraries easily accessible via mobile devices.

\section{Conflict of Interest}

None.

\section{Source of Funding}

None.

\section{References}

1. Lori B. Mobile technologies for libraries- A list of mobile applications and resources for development. Coll Res Libr News 2011;72(4):222-8.

2. Cummings J, Merrill A, Borrelli S. The use of handheld mobile devices: their impact and implications for library services. Emerald, Librry Hi Tech, 2009;28(1):22-40. Retrieved from:

https://research.wsulibs.wsu.edu:8443/jspui/bitstream/2376/23 25/1/Use\%20of\%20han dheld\%20mobile\%20devices.pdf 
3. Kate K, Frank S. Handheld libraries using mobile technologies in the academic library. Feature, 2011;31(6).

4. Lippincott, Joan, K. (2008). Mobile technologies, mobile users: implications for academic libraries. Assoc Res Libr 2008;261:1-4. Retrieved from: http://www.arl.org/bm doc/arlbr-261.pdf/

5. Malathy S, Kantha P. Application of mobile technologies to libraries. DESIDOC J Libr Inf Technol 2013;33(5):361-6.

6. Rao NS, Brahmaiah G. Mobile library services and technologies: a study. Int J Res Libr Sci 2016;2(2):59-66.
7. Saxena A, Yadav RD. Impact of mobile technology on libraries: a descriptive study. Int J Digit Libr Serv, 2013;3(4):1-13.

8. Singh G, Arora T. Usage of e- resources in college libraries in Delhi. Libr Herald 2010;48:363-75.

9. Lal VM, Lal MS, Shivani G. Use of mobile and wireless technology in Indian libraries. Int J Eng Computer Sci 2013;2(6):1799-805.

How to cite: Bhoj HS. Mobile based library services. IP Indian J Libr Sci Inf Techno 2020;5(2):61-4. 